\title{
O RESPEITO AOS POVOS INDÍGENAS À LUZ DO DIREITO INTERNACIONAL CONTEMPORÂNEO
}

\section{RESPECT FOR INDIGENOUS PEOPLE IN THE LIGHT OF CONTEMPORARY INTERNATIONAL LAW}

ISABELA MOREIRA DO N. DOMINGOS

Mestranda (bolsista CAPES) em Direito Econômico e Sustentabilidade pela Pontifícia Católica do Paraná (PUCPR). Pós-Graduada em Penal Econômico pela Fundação Escola do Ministério Público - FEMPAR. Graduada em Direito pelo Centro Universitário Curitiba (UNICURITIBA) Membro Grupo de Pesquisa Direito Empresarial e Cidadania no Século XXI, Hermenêutica Constitucional e a Concretização dos Direitos Fundamentais na Pós-Modernidadee Direito à Saúde e Cidadania, ambos do Unicuritiba (CNPQ). Associada do Conpedi. Advogada. E-mail: isabela.xr@hotmail.com

\section{LUIZ HENRIQUE SANTOS DA CRUZ}

Mestrando (bolsista CAPES) em Direito Empresarial pelo Centro Universitário Curitiba (UNICURITIBA). Pós-graduado em. Membro do Grupo de Pesquisa Direito Empresarial e Cidadania no Século XXI e do Sustentabilidade e Direito (ambos vinculados ao CNPQ/UNICURITIBA). Associado do Conpedi. Advogado. E-mail: Ihenrique.s.adv@gmail.com.

\section{RESUMO}

O direito internacional sofreu diversas influências dos processos hegemônicos de exploração econômica de países tidos como não civilizados. No presente, a denominação terminológica foi alterada para nações "desenvolvidas" e 
Personalidade Acadêmica Homenageada:

Raymundo Juliano Feitosa (Universidade Federal do Rio Grande do Norte - UFRN)

"subdesenvolvidas", esta última carrega as cicatrizes do domínio colonial e imperial. Os indivíduos mais afetados em razão dessa assimetria nas relações de poder são os que habitam em países de Terceiro Mundo, seja pela ineficiência da gestão governamental na promoção de direitos básicos como saúde, educação moradia e emprego, como a proliferação de multinacionais para a exploração de recursos naturais. Nesse sentido, o Brasil para alcançar índices globais de desenvolvimento tem apostado na presença de multinacionais para a exploração de suas riquezas, se distanciando cada vez mais da ética e do desenvolvimento sustentável, o que afeta diretamente as comunidades ribeirinhas, população indígena e quilombola e habitantes das cidades onde as empresas atuam. Fato que tem chamado atenção das organizações internacionais para a proteção dessas pessoas em situação de vulnerabilidade, sobretudo, das comunidades indígenas que estão sendo aniquiladas ao longo do processo de colonização. Acrescenta-se que a Corte Interamericana de Direitos Humanos é responsável por decidir acerca dos direitos indígenas na perspectiva internacional. Os direitos humanos no cenário tradicional não refletem a realidade indígena, é preciso adaptar conforme as peculiaridades do caso concreto, sob pena de imposição hegemônica de costumes eurocêntricos que aceleram o processo de desculturação das tribos. De fato, a descolonização se torna um meio de soberania jurídica das nações europeias, d esencadeando mecanismo de exclusão sobre aqueles considerados incivilizados (atualmente denominado de países subdesenvolvidos). O colonialismo surge como um processo de segregação entre os povos, diferenciando as civilizações modernas do ocidente civilizado e o resto do mundo como bárbaro. Nessa linha, o modelo de produção capitalista expandiu a miséria e impulsionou ações individualistas que repercutiram na degradação ambiental afetando diretamente todos aqueles que necessitam da sadia qualidade do ecossistema para a sua subsistência. Diante dos fatos apresentados, cada vez mais os pesquisadores e juristas nacionais necessitam tecer um olhar crítico sobre a história do direito internacional, isto significa lidar com posições no campo da ética, possibilitando a reflexão acerca da influência do passado no mundo contemporâneo. Portanto, somente com o respeito as soberanias de outros povos e nações, é possível que o direito internacional rompa a tradição violenta contra grupos étnicos 
Personalidade Acadêmica Homenageada:

Raymundo Juliano Feitosa (Universidade Federal do Rio Grande do Norte - UFRN)

marginalizados e consiga implementar novas alternativas para a organização jurídica internacional, em consonância com os fundamentos da dignidade humana e a proteção ambiental. A pesquisa utilizou da metodologia hipotético-dedutiva para a confirmação das hipóteses ora apresentadas.

PALAVRAS-CHAVES: Sustentabilidade; Desenvolvimento; Direitos Humanos; Povos Indígenas; Desculturação.

\section{REFERÊNCIAS}

ANGHIE, Antony; KOSKENNIEMI, Martti; ORFORD, Anne. Imperialismo y Derecho Internacional. Estudio Preliminar de Luis Eslava, Liliana Obregón y René Urueña. Nuevo Pensamiento Jurídico, Universidad de los Andes, Pontificia Universidad Javeriana. 2016.

ARENDT, Hanna. The Origius of Totalitariauism, Ver. Ed. New York: Harcourt, 1973.

CAMPELLO, Lívia Gigher Bósio. Os direitos de consulta e participação dos povos indígenas e a prática da corte interamericana de direitos humanos. Revista Jurídica, vol. 03, $n^{\circ}$. 52, p. 300-323, Curitiba, 2018. DOI: 10.6084/m9.figshare.7371104

GALINDO, George Rodrigo Bandeira. Para que serve a história do internacional?. Revista de Direito Internacional, Brasília, v. 12, n. 1, p. 338-354, 2015.

MENESES, Maria Paula G.. O 'indígena' africano e o colono 'europeu': a construção da diferença por processos legais, e-cadernos ces [Online], $07 \mid 2010$, colocado online no dia 01 março 2010, consultado a 15 janeiro 2019. URL: http://journals.openedition.org/eces/403; DOI : 10.4000/eces.40.

REMIRO BROTÓNS, António et al. Derecho Internacional: curso geral. Valência: Tirant lo Blanch, 2010. 